\title{
State space analysis of flexible manufacturing cell using timed colored Petri nets
}

\author{
Sanjib Kumar Saren ${ }^{1, *}$, and Florin Blaga ${ }^{2}$ \\ ${ }^{1}$ Mechatronics Department, University Of Oradea, Romania \\ ${ }^{2}$ Industrial Engineering Department, University Of Oradea, Romania
}

\begin{abstract}
In this paper we focus on analysis and evaluation of flexible manufacturing cell using time colored Petri nets. We basically model the system with respect to time to observe relation between each place and transition through arcs. The model is designed used CPN (Colored Petri nets) tools software. The FMC (Flexible Manufacturing Cell) model is studied from the Faculty of Engineering Management and Technology, University of Oradea. In this experiment we evaluate system analysis with respect to time using timed colored Petri net and describe the state space property of the flexible manufacturing cell using two cases first model with the two different place of machine and second model with compact machine place. The simulation results for the both system shows that the steps required for complete the simulation is same for both cases even though the number of place and the number of transition are different in both models. Also we discussed state space properties for both models to identify their properties during simulation.
\end{abstract}

\section{Introduction}

Today's world industries focus on produce quality product with less time and less money in manufacturing system. It's the best way to focus on simulation of the system to predict appropriate result before apply on real system. We focus on FMC (Flexible Manufacturing System) system to simulate the model to predict results. They described utilization of colored petri nets as a high level language system for design the system and analysis different state of the system, place invariants, occurrence graph and also use of computer tools for CPN (Colored Petri nets) [1]. Provide idea and motivation of development concurrent system using colored petri nets and CPN tools to development of model for the system [2]. Described colored petri net is discrete-event modeling language combination with functional programming language Standard ML provides graphical notation, modeling concurrency, communication, and synchronization. Also mention use of time in colored petri nets according to modeling aspect [3]. Addressed state space analysis in Colored Petri Nets to define each possible behavioral property for node and arcs in the concurrent system [4]. Described use of colored petri nets tools for modeling, editing, simulating and analyzing untimed and timed nets with state space analysis [5]. Author described FMC

\footnotetext{
* Corresponding author: sanjibksaren@gmail.com
} 
system development using timed colored Petri nets [6]. Derived method for state space properties in colored Petri nets [7]. Time-transition Petri net (TTPN) used to model Flexible manufacturing system based on scheduling problems. TTPN involves less transition and places for this model and to achieved the minimum Makespan in scheduling problem, they developed $A^{*}$ algorithm which helps to search deeper successor in few cases. [8]. In Manufacturing Systems Petri Net (PN) is useful graphical mathematical tool to analysis behavior and verifies properties in details. They mentioned state space to easily identify bounded ness, liveness and fairness in manufacturing system [9]. In this paper, they proposed systematized hybrid methodology in timed hierarchical colored Petri nets to model the flexible manufacturing system to find the better productivity setup for the system. They also explored state space to find the properties from the system likes liveness, boundedness, and reversibility [10].

\section{Descriptions of the flexible manufacturing cell}

The flexible manufacturing cell layout consisting of Power station, Evacuation station, and Milling machine CNC CONCEPT MILL 55, Control equipment (FANUC) of milling machine, Lathe CNC CONCEPT TURN 55, Control equipment (FANUC) the lathe, Mitsubishi RV-2AJ robot and Handle the moving robot. In Figure 1, the flexible manufacturing cell from the Faculty of Engineering Management and Technology, University of Oradea present below.

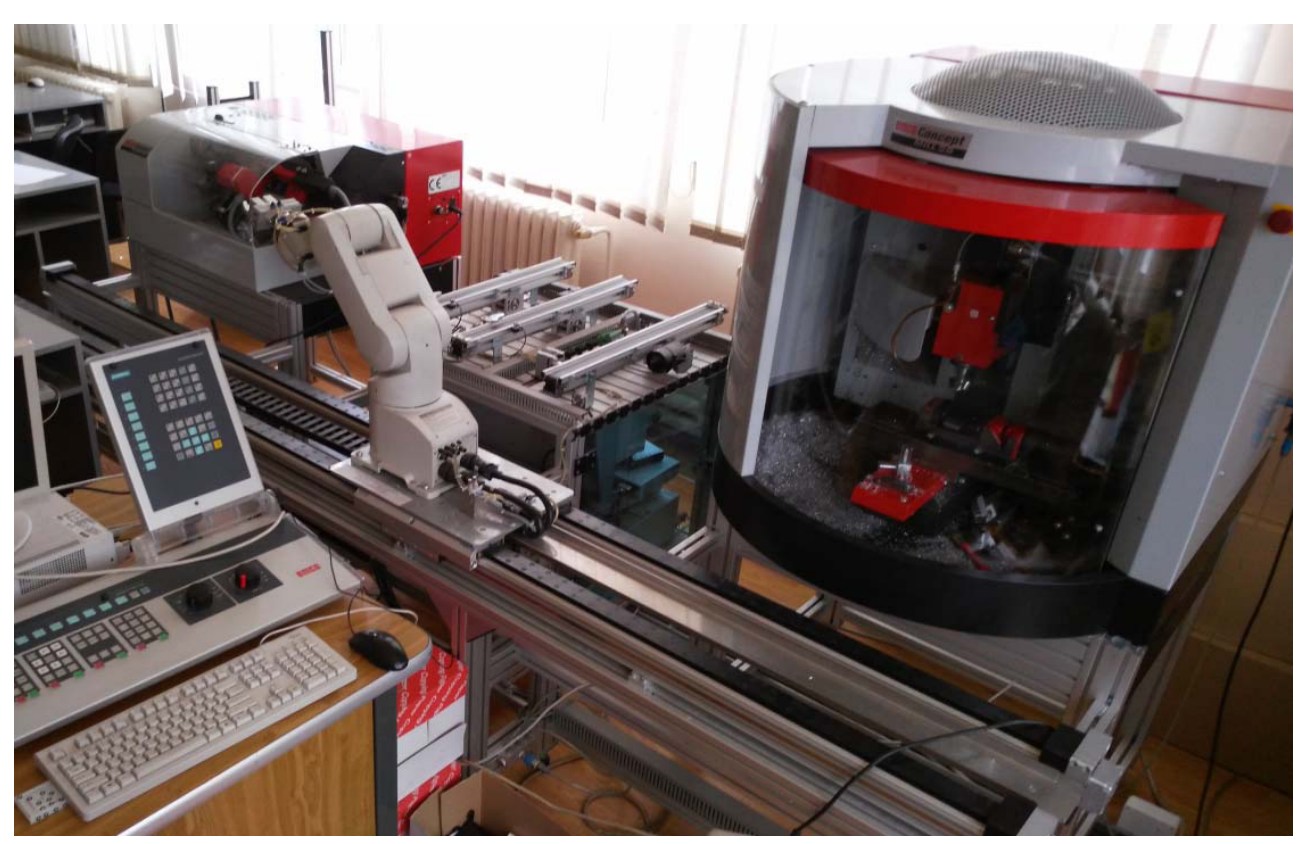

Fig 1. Flexible Manufacturing Cell (Faculty of Engineering Management and Technology, University of Oradea). 


\section{Descriptions of the function of the system with time}

\subsection{Define the time of sequences for two different FMC model}

The processing time for the first model define with initial time $\mathrm{T}_{0}=420 \mathrm{~s}$. The parts will arrive to the system according to the short proceeding time. Its mean the revolute parts (P1) arrive first in the system, then another revolute part (P2) will arrive in the CNC CONCEPT TURNS 55 (M1). After complete of revolute parts robot (R1) loading prismatic part (P3) in CNC CONCEPT MILL 55 (M2). Then last part (P4) is processing on the CNC CONCEPT MILL 55 (M2) to complete the operation. So, the sequence is P1-P2-P3-P4 in the first model. The second model is more compact than first model. Here the initial time consider $\mathrm{T}_{0}=0 \mathrm{~s}$. The first part $(\mathrm{P} 1)$ will arrive in the system at time $\mathrm{T}_{0}=0 \mathrm{~s}$. Second part (P3) will arrive at $400 \mathrm{~s}$ in the system, third part (P4) will arrive at $1450 \mathrm{~s}$ and last part (P2) will arrive at $2000 \mathrm{~s}$ in the system. So, the time sequence for the second model will be P1-P3P4-P2. In the second model transition time is used to define the processing time. The part will be processing on transition T2. The instruction of time in transition T2 is @ + (if (p, m) $=(\mathrm{P} 1, \mathrm{M} 1)$ then 420 else if $(\mathrm{p}, \mathrm{m})=(\mathrm{P} 2, \mathrm{M} 1)$ then 540 else if $(\mathrm{p}, \mathrm{m})=(\mathrm{P} 3, \mathrm{M} 2)$ then 1080 else 1260 , all the values in seconds.

\subsection{Processing time of parts for both models}

Color with time will be developed on the basis of 1) Color timing (marks), 2) Transition timing, 3) Arcs timing. The time considered with the job processing time in the simulation. In the first model time for arrivals of the parts associated with the only processing time. We define the simulation time $(\mathrm{P} 1, \mathrm{M} 1)=420 ;(\mathrm{P} 2, \mathrm{M} 1)=540 ;(\mathrm{P} 3, \mathrm{M} 2)=1080 ;(\mathrm{P} 4, \mathrm{M} 2)=$ 1260. The processing parts are shown below in the Figure 2.

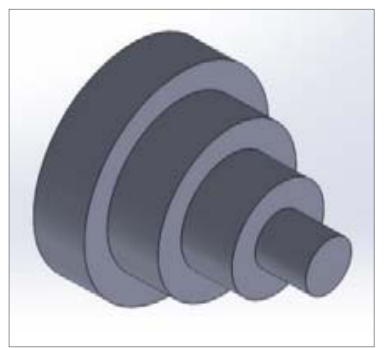

(a)

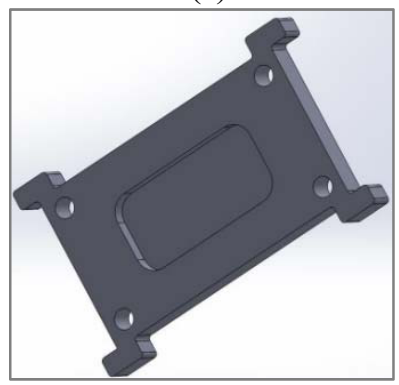

(c)

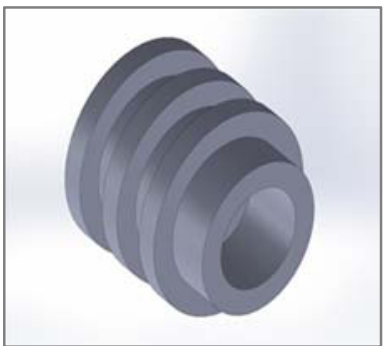

(b)

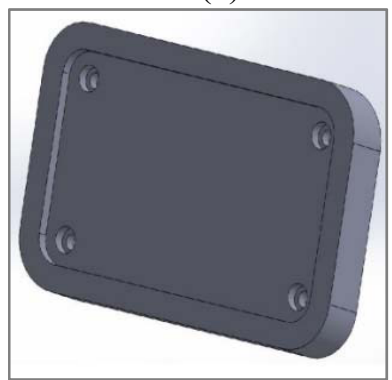

(d)

Fig. 2. (a) \& (b) revolute and (c) \& (d) prismatic parts are processing on $\mathrm{CNC}$ turning and milling. 


\section{Modeling of the system using colored Petri nets with respect to time}

\subsection{Color and variable definition for the first system}

Colors define for each machine: Lathe CONCEPT TURN55 CNC (closet lathe = with M1): Lathe $=\{$ M1 $\}$ Milling CNC CONCEPT MILL55 (colset Milling = with M2): Milling = $\{\mathrm{M} 2\}$. The color set for different parts with time: (colset pieceL = withP1|P2 timed): pieceL $=\{\mathrm{P} 1 @ 420 ; \mathrm{P} 2 @ 540\} ;$ (colset pieceM = withP3|P4 timed): pieceM $=\{\mathrm{P} 3 @ 1080$, $\mathrm{P} 4 @ 1260\}$. Colors define for robot: $($ closet robot = with R1 timed): Robot $=\{\mathrm{R} 1 @ 0\}$. The color set is define for two different machine and different parts, that's cause the system is complex, for this reason color must define for each machine with piece. For lathe the color is "colourL" and for milling "colourM". (Colset colourL = product piece*lathe timed) ;( Colset colourM $=$ product piece*Milling timed). During modeling the system, we define different machine and different parts. Each part is processed in particular machine it defines in the system, the definition for the complex color for lathe is "programL" and for milling is "programM". (Colset programL = product piece*lathe timed); (Colset programM = product piece*Milling timed). The product and machine have this complex color pairs to run the system. It can be defined by: $\{\mathrm{P} 1, \mathrm{M} 1\},\{\mathrm{P} 2, \mathrm{M} 1\}$ and $\{\mathrm{P} 3, \mathrm{M} 2\},\{\mathrm{P} 4, \mathrm{M} 2\}$. Color defines for Variables: In color petri nets network connection between place and transition define by arcs. In this model arc is assigned with the variables to create connection between place and transition. The variable for turning part is defined by " $p L$ " it has values (P1, P2) and for milling part "pM" its values are (P3, P4).

$$
\begin{aligned}
& p L \in\{p 1, p 2\} \\
& p M \in\{p 3, p 4\}
\end{aligned}
$$

The variables for machine M1 and M2 are defined by respectively $\mathrm{m} 2$ and $\mathrm{m} 1$.

$$
\begin{aligned}
& m 1 \in\{m 2\} \\
& m 2 \in\{m 1\}
\end{aligned}
$$

The variable for robot can be defined by " $r$ " which has value:

$$
r \in\{R\}
$$

The model must be creating connection between the parts and machine in colored Petri nets through the variables which mention in arcs to establish the system.

$$
\begin{aligned}
& p L X m 2 \in\{P 1, M 1\}\{P 2, M 1\} \\
& p M X m 1 \in\{P 3, M 2\}\{P 4, M 2\}
\end{aligned}
$$

The place position, the token position and transitions positions are mentioned below in the Table 1, Table 2 and Table 3 for the first flexible manufacturing cell with two different places for machine respectively lathe and milling. In Table 1 contains the descriptions for each place with complexity of color and interpretations. Each complex color defines name respectively "programL", "programM", "pieceL", "pieceM", "lathe", "milling" and "robot". In Table 2 describe about the initial and final token position with respect to time and Table 3 describe the transitions and arc time in the system. Arc timing consider from 
place P13 to connect with the required transitions respectively T1, T3, T4, T5, T7 and T8. During modeling the system each parameters is important to build the system.

Table 1. Place Position.

\begin{tabular}{|c|c|c|}
\hline Places & Complexity of color & Interpretation \\
\hline P1 & complex color "programL" & Raw materials in stock for turning. \\
\hline P2 & complex color "programL" & Turning Parts in robot gripper (R1) \\
\hline P3 & complex color "programL" & Turning parts in machine for processing (M1) \\
\hline P4 & complex color "pieceL" & Part is unloading from lathe by robots (R1) \\
\hline P5 & complex color "pieceL" & Finish turning part store in storage. \\
\hline P6 & complex color "programM" & Raw materials in stock for milling. \\
\hline P7 & complex color "programM" & Milling Parts in robot gripper(R1) \\
\hline P8 & complex color "programM" & Milling parts in machine for processing (M2) \\
\hline P9 & complex color "pieceM" & Part is unloading from milling by robots (R1) \\
\hline P10 & complex color "pieceM" & Finish mill part store in storage. \\
\hline P11 & complex color "lathe" & Lathe (M1) \\
\hline P12 & complex color "milling" & Milling (M2) \\
\hline P13 & complex color "robot" & Robot (R1) \\
\hline
\end{tabular}

Table 2. Token Position.

\begin{tabular}{|c|c|c|}
\hline Places & Initial Token position in system & $\begin{array}{c}\text { Final Token } \\
\text { position in system }\end{array}$ \\
\hline P1 & (P1, M1)@420;(P2,M1)@540 & - \\
\hline P2 & - & - \\
\hline P3 & - & - \\
\hline P4 & - & P1@428;P2@548 \\
\hline P5 & - & - \\
\hline P6 & (P3, M2)@1080;(P4,M2)@1260 & - \\
\hline P7 & - & - \\
\hline P8 & - & - \\
\hline P9 & - & P3@1088;P4@1268 \\
\hline P10 & - & M1 \\
\hline P11 & M1 & M2 \\
\hline P12 & M2 & R1@8 \\
\hline P13 & R1@0 & - \\
\hline
\end{tabular}


Table 3. Transitions Position.

\begin{tabular}{|c|c|c|}
\hline Transitions & \multicolumn{1}{|c|}{ Interpretation } & Arc timing \\
\hline T1 & Turning part is load by robot (R1) & P13- T1=r@+8 \\
\hline T2 & Part is processing in lathe (M1) & - \\
\hline T3 & Part is unload by robot (R1) & P13- T3=r@+8 \\
\hline T4 & Part is ready to storage & P13- T4=r@+8 \\
\hline T5 & milling part is load by robot (R1) & P13- T5=r@+8 \\
\hline T6 & Part is processing in milling (M2) & - \\
\hline T7 & Mill Part is unload by robot(R1) & P13- T7=r@+8 \\
\hline T8 & Mill Part is ready to storage & P13- T8=r@+8 \\
\hline
\end{tabular}

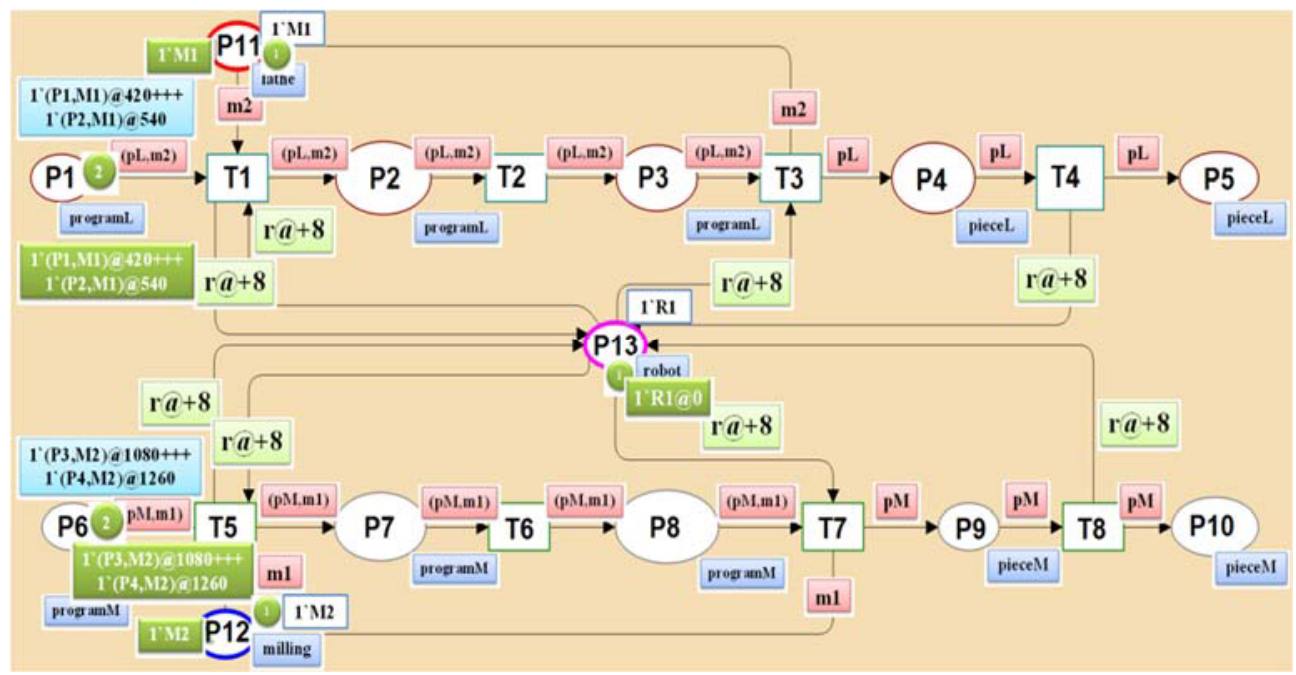

Fig. 3. Two different machine place model using timed colored petri nets condition with initial stage of simulation.

In Figure 3, present the initial stage of the simulation. It appears that during modelling place P1, P6, P11, P12 and P13 contains the processing time. in this system place P1 contain processing time for lathe parts respectively $420 \mathrm{~s}$ and $540 \mathrm{~s}$ and place P2 contain processing time for milling parts respectively $1080 \mathrm{~s}$ and $1260 \mathrm{~s}$ and initial robot time show in the system1'R1@0. In P1, P6, P11, P12, P13 shows token position respectively 2, 2, 1, 1, 1. P11 and P12 shows the lathe machine $1{ }^{`} \mathrm{M} 1$ and milling machine $1{ }^{`} \mathrm{M} 2$. It is observed that when the model is ready the required program appears in green colour means the all the places, arc and transitions arc connected in proper way to simulate the manufacturing system model. In Figure 4, shows final stage of simulation. The token take move from initial place to final place to fulfil the simulation process and the time and token is appeared in the place P5, P10 and P13. 


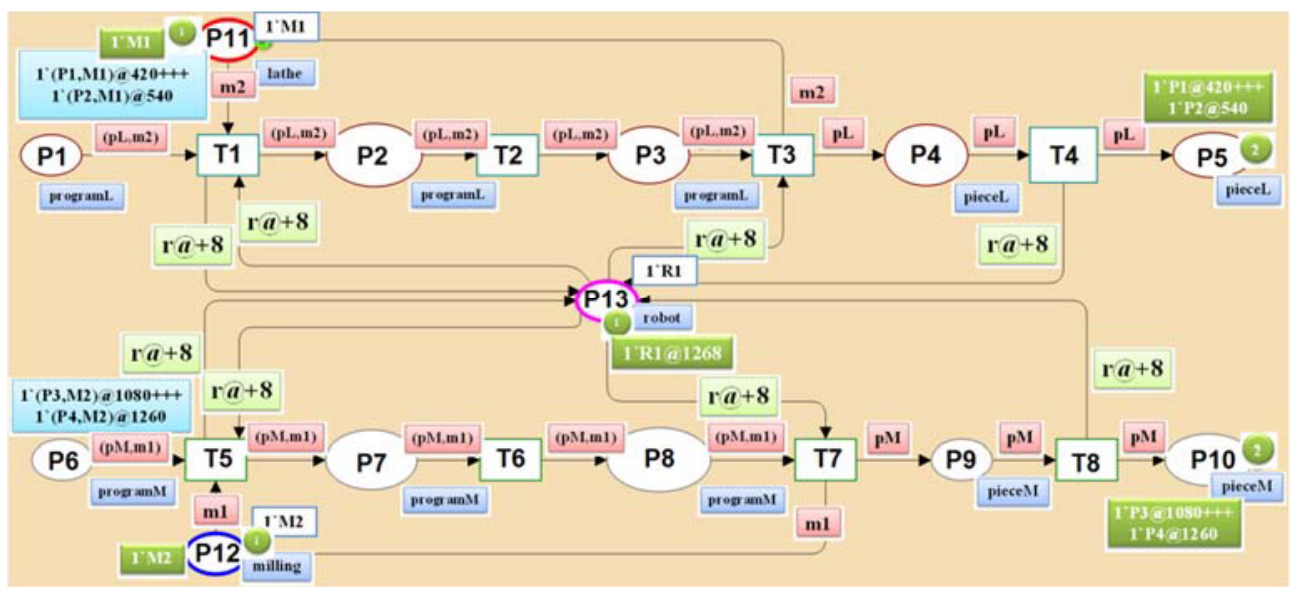

Fig. 4. Two different machine place model using timed colored petri nets condition with final stage of simulation.

\subsection{Color and variable definition for the second system}

Colors define for each machine: The color set for lathe CONCEPT TURN55 CNC and for milling CNC CONCEPT MILL55. So the value for machine is (colset Milling = with $\mathrm{M} 1 \mid \mathrm{M} 2)$, it defines: Machine $=\{\mathrm{M} 1, \mathrm{M} 2\}$. The color set for different parts are mentioned with the color. The value for the parts is: P1, P2, P3, and P4. The definitions of this value are: $($ colset piece $=$ withP1|P2| P3|P4), Piece $=\{\mathrm{P} 1 @ 420, \mathrm{P} 2 @ 540, \mathrm{P} 3 @ 1080$, and P4@1260\}. The robot is associated with color "robot". It has value R1. (colset robot = with $\mathrm{R} 1)$ is the definition for robot in the model. Robot $=\{\mathrm{R} 1 @ 0\}$. Color defines for Variables: In color petri nets network connection between place and transition define by arcs. In this model arc is assigned with the variables to create connection between place and transition. The variable for parts " $\mathrm{P}$ " value is:

$$
p \in\{p 1, p 2, p 3, p 4\}
$$

The variables for machine M1 and M2 are defined by respectively $\mathrm{m} 2$ and $\mathrm{m} 1$.

$$
m \in\{M 1, M 2\}
$$

The variable for robot can be defined by "r" which has value:

$$
r \in\{R\}
$$

The model must be creating connection between the parts and machine in colored petri nets through the variables which mention in arcs to establish the system.

$$
p \times m \in\{(P 1, M 1),(P 2, M 1),(P 3, M 2),(P 4, M 2)\}
$$

The place position, the token position and transitions positions are mentioned below in the Table 4, Table 5 and Table 6 for the first flexible manufacturing cell with compact machine place respectively lathe and milling. In Table 4, contains the descriptions for each place with complexity of color and interpretations. Each complex color defines name respectively "program", "piece", "machine" and "robot". In Table 5, describe about the initial and final token position with respect to time and Table 6 describe the transitions and arc time in the system. Arc timing consider from place P7 to connect with the required 
transitions respectively $\mathrm{T} 1, \mathrm{~T} 2, \mathrm{~T} 3$ and $\mathrm{T} 4$.

Table 4. Place Position.

\begin{tabular}{|c|c|c|}
\hline Places & Complexity of color & Interpretation \\
\hline P1 & complex color "program" & Raw materials in stock. \\
\hline P2 & complex color "program" & Parts in robot gripper (R1) \\
\hline P3 & complex color "program" & Part in machine for processing.(M1 \& M2) \\
\hline P4 & complex color "piece" & Part is unloading by robot (R1) \\
\hline P5 & complex color "piece" & Finish part store in storage. \\
\hline P6 & complex color "machine" & Working machine (M1 \& M2) \\
\hline P7 & complex color "robot" & robot (R1) \\
\hline
\end{tabular}

Table 5. Token Position.

\begin{tabular}{|c|c|c|}
\hline Places & Initial Token position in system & Final Token position in system \\
\hline P1 & $(\mathrm{P} 1, \mathrm{M} 1) ;(\mathrm{P} 2, \mathrm{M} 1) ;(\mathrm{P} 3, \mathrm{M} 2) ;(\mathrm{P} 4, \mathrm{M} 2)$ & - \\
\hline P2 & - & - \\
\hline P3 & - & - \\
\hline P4 & - & - \\
\hline P5 & - & $(\mathrm{P} 1, \mathrm{P} 2, \mathrm{P} 3, \mathrm{P} 4)$ \\
\hline P6 & $(\mathrm{M} 1, \mathrm{M} 2)$ & $(\mathrm{M} 1, \mathrm{M} 2)$ \\
\hline P7 & $\mathrm{R} 1$ & $\mathrm{R} 1$ \\
\hline
\end{tabular}

Table 6. Transitions Position.

\begin{tabular}{|c|c|c|}
\hline Transitions & Interpretation & Arc timing \\
\hline T1 & Part is loading by robot (R1). & P7-T1=r@+8 \\
\hline T2 & Part is processing (M1 \& M2). & P7-T2=r@+8 \\
\hline T3 & Part is unloading by robot (R1). & P7-T3=r@+8 \\
\hline T4 & Part is ready to storage & P7-T4=r@+8 \\
\hline
\end{tabular}

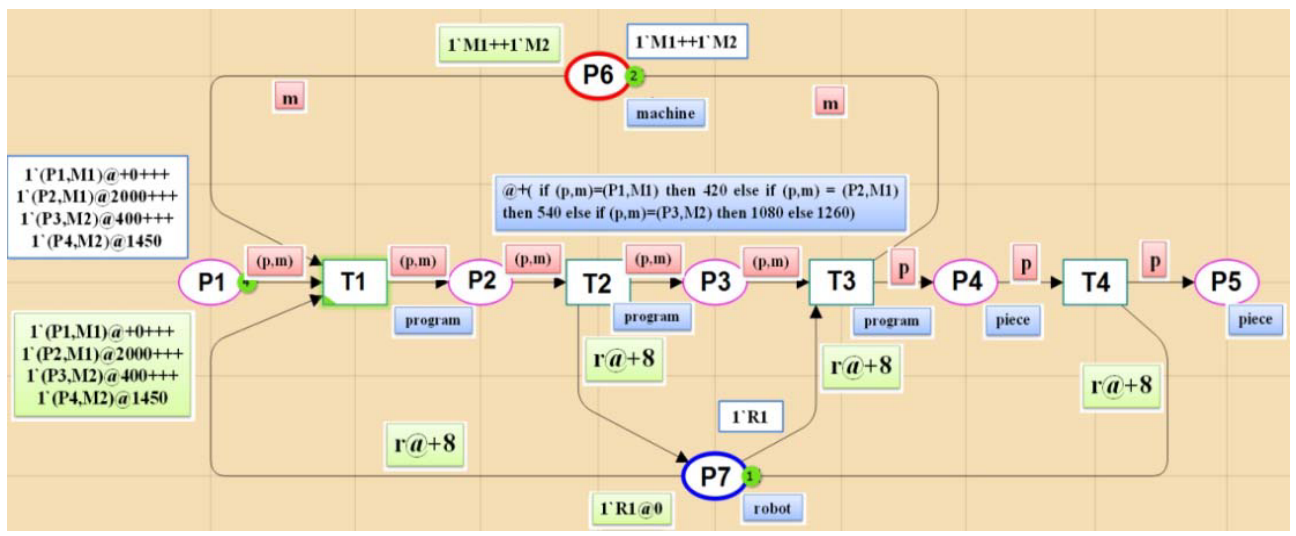

Fig. 5. Compact machine place model using CPN toots with respect to time with initial condition of simulation. 


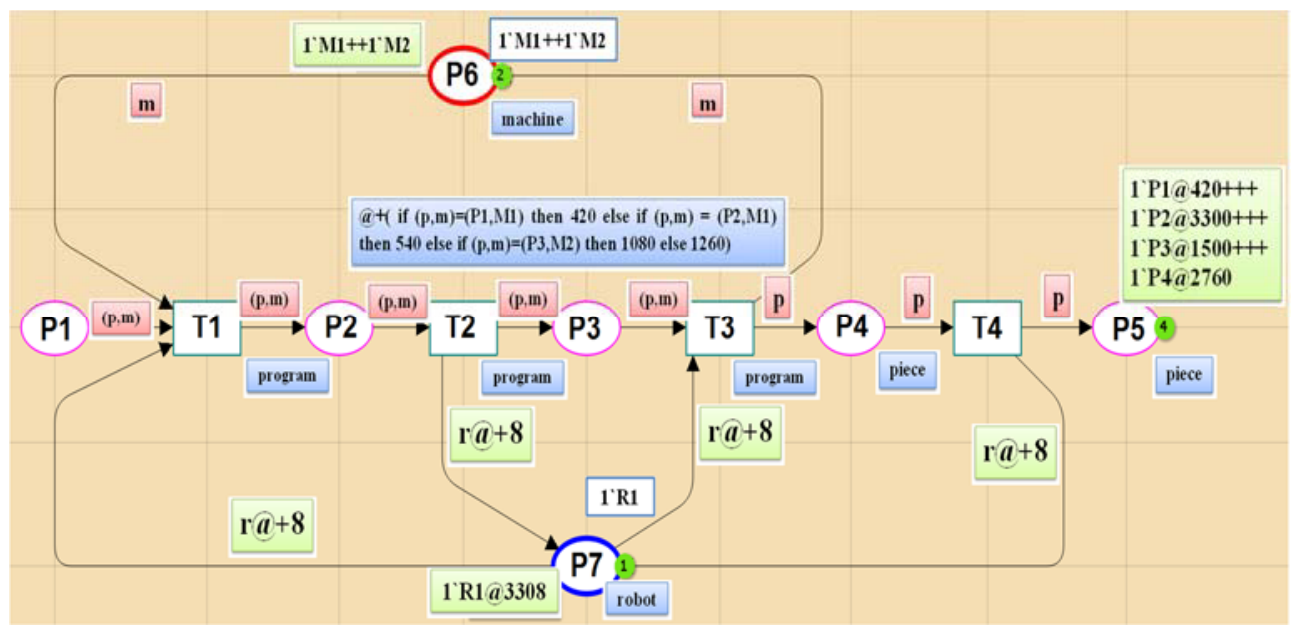

Fig. 6. Compact machine place model using CPN toots with respect to time with final condition of simulation.

In Figure 5, present the initial stage of the simulation for the compact machine place. It appears that during modelling place P1 contains the job arrival time for parts and P7 contains robot loading and unloading time. In this system processing time for lathe parts respectively $420 \mathrm{~s}, 540 \mathrm{~s}$ and processing time for milling parts respectively $1080 \mathrm{~s}$ and 1260 $\mathrm{s}$ and here also initial robot time show in the system 1 'R1@0. In P1, P6 and P7shows token position respectively 4, 2, 1. Place P6 show the machine 1'M1+1 'M2. In Figure 6, shows final simulation for the model. The token take move from P1 to P5 and it appears 4 tokens in place P5, the token position for $\mathrm{P} 7$ is 1 and for place the token position is 2 respectively.

\section{First and second models simulation results}

FMC system consisting of two machines Lathe CNC CONCEPT TURNS 55 (M1) and Milling machine CNC CONCEPT MILL 55 (M2), each machine is served by Mitsubishi $\mathrm{RV}-2 \mathrm{AJ}$ robot (R1) for loading and unloading for the parts and places the parts for storage area. In FMC system parts are moving through conveyor from one station to other stations. Robot (R1) loads the parts from pallet to both machines (M1 and M2) according to operation. In this simulation four parts are processing in two different machines. We consider robot loading and unloading time $8 \mathrm{~s}$ for each operation.

In first model Figure 4, Job is according to the less processing time in the system. According to this sequence two turning part is processing in the lathe with time $420 \mathrm{~s}$ and $540 \mathrm{~s}$ respectively. Then two different milling parts is processing according to the time with $1080 \mathrm{~s}$ and $1260 \mathrm{~s}$. If robot loading and unloading time is consider with the job processing time then job completion time sequence will be $428 \mathrm{~s}, 548 \mathrm{~s}, 1088 \mathrm{~s}$ and $1268 \mathrm{~s}$. The arc timing is considered $\mathrm{r} @+8 \mathrm{~s}$ in the system. Robot will take $1268 \mathrm{~s}$ complete the total simulation.

In Figure 4, we see that Place P1, both parts and machine (P1, M1) and (P2, M1) and in Place P2, (P3, M2) and (P4, M2) appears. During the simulation it is observed that only the finishing turning parts are reached in place P6 as a P1, P2 and the milling parts reached in place P10 as a P3, P4. Also we observed that the movement of the token from one place to another place. During simulation the information is transfer through the one place to another place by adding transition through arcs. This arcs contain required time and connecting program between the transition and place. When place send the information 
through arcs is fire and received the information in transition and send it in another place. The whole system follows the same procedure to run the system.

In second model Figure 6, we consider two machines in one place. Here we consider job arrival time in the system. The job $\mathrm{P} 1$ will arrived at $\mathrm{T}_{0}=0$ seconds in the system, $\mathrm{P} 3$ at 400 s, P4 at $1450 \mathrm{~s}$ and P2 at $2000 \mathrm{~s}$ in the system. The robot loading and unloading time will take $8 \mathrm{~s}$. The arc timing is considered to connect between the place and transition. The arc timing is $\mathrm{r} @+8$. From simulation we found the total job processing time in the system. The time for $\mathrm{P} 1=420 \mathrm{~s}, \mathrm{P} 3=1500 \mathrm{~s}, \mathrm{P} 4=2760 \mathrm{~s}$ and $\mathrm{P} 2=3300 \mathrm{~s}$. The robot will take $3300 \mathrm{~s}$ to complete the simulation. Here in second model, all the token is place in $\mathrm{P} 1$ and all the parts and machine are values are appeared as a (P1, M1), (P2, M1), (P3, M2), (P4, M2). At the end of the simulation only the finished parts are reached in place P5 as a parts (P1, P2, P3, P4).

In both cases, it is found that total 16 steps required finishing the simulation. If we see carefully for both cases the number of place is different. In two different machine place there are total 13 place, 8 transitions and for compact machine place there are total 7 place and 4 transitions. But the required steps are same for both models.

\section{First and second models state space analysis}

We analyze State space properties for both models. In state space we generate SCC graph and reachability properties. Also derives few properties during simulation which are Boundedness property, Home Properties, Liveness Properties and Fairness Properties. Basically in state space we found the behavior of the system for each place and transition. During generate state space graph it shows nodes in paths mode which shows node list in the system. In state space graph shows each nodes and arcs information of system behavior. Just click on the any nodes and arcs it shows the accurate condition of the system behavior. In Figure 4, we see in arc 1 shows information (1:1=>@420 model_1`T1 1\{r=R1, pL=P1, $\mathrm{m} 2=\mathrm{M} 1\}$ so in each arc carry information about status of machine, robot and part. Each node also carries information of system .Nodes 17 shows 17@1260, place position 5 for part P1@420, P2@540 and place10 for P3@1080, P4@1268 \& place11 and 12 for machines M1 and M2.

In Figure 7, shows the system behavior of the first model. Statistics of first model observed state space and SCC graph it shows total 17 nodes and 16 arcs are required to complete the processing of system. For first model Initial Marking is not a home marking. In liveness properties there are no dead and live transitions Instances in the system. For first system Dead Markings is 17. In fairness properties no infinite occurrence sequences.

In Figure 8, shows the state space for second model. Statistics of second model verified observed state space and SCC graph here also required 74 nodes and 78 arcs to complete the system. Here also initial marking is not a home marking but here we found dead transition in the system. For second system dead markings are 74, 73, 72, 65, 64, and 63. Here we found from the both system, different nodes and arcs are required to complete the operation because the place and transition are different in both systems. The different also observed in SCC graph and dead marking in for both models. In state space analysis we found few properties in both systems. The analysis describes the information about each nodes and arcs in the system. How the both system works we got information through the state space. 


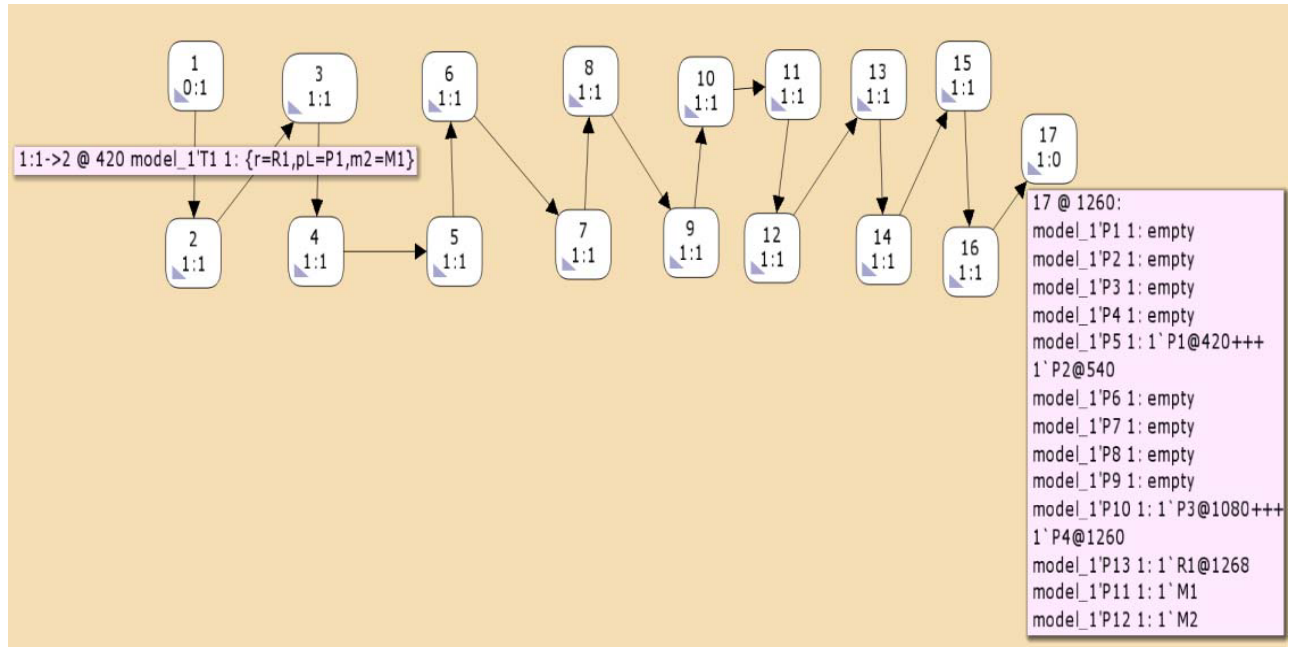

Fig. 7. State space diagram view for two different machine place model.

In Table 7, we present the boundedness properties for the two different machine place and mentioned best possible multi set bounds for the system. In place P1 appears 1 '(P1,M1)++1 '(P2,M1) with upper bound 2 means it has 2 token when its moves to the token its reached in place P5 with upper bound 2 in place P5 which appears 1'P1++1'P2 in the system. If we see the upper bound and lower bound in the Table 7 its means it's all token position during the simulation which observed. And it's also clear that only finishing parts are appears end of the simulation as a $1^{`} \mathrm{P} 1++1^{`} \mathrm{P} 2$ and $1^{`} \mathrm{P} 3++1{ }^{`} \mathrm{P} 4$ respectively in place P5 and P9.

Table 7. Best Integer Bounds for first Model.

\begin{tabular}{|c|c|c|c|c|}
\hline $\begin{array}{l}\text { Best Integer } \\
\text { Bounds }\end{array}$ & upper & lower & $\begin{array}{c}\text { Best Upper Multi-set } \\
\text { Bounds }\end{array}$ & $\begin{array}{c}\text { Best Lower Multi-set } \\
\text { Bounds }\end{array}$ \\
\hline model_1'P10 1 & 2 & 0 & $1 ` \mathrm{P} 3++1 ` \mathrm{P} 4$ & Empty \\
\hline model_1'P1 1 & 2 & 0 & $1^{\prime}(\mathrm{P} 1, \mathrm{M} 1)++1^{\prime}(\mathrm{P} 2, \mathrm{M} 1)$ & Empty \\
\hline model_1'P11 1 & 1 & 0 & 1’M1 & Empty \\
\hline model_1'P12 1 & 1 & 0 & $1{ }^{\prime} \mathrm{M} 2$ & Empty \\
\hline model_1'P13 1 & 1 & 0 & 1’R1 & Empty \\
\hline model_1'P2 1 & 1 & 0 & $1^{\prime}(\mathrm{P} 1, \mathrm{M} 1)++1^{\prime}(\mathrm{P} 2, \mathrm{M} 1)$ & Empty \\
\hline model_1'P3 1 & 1 & 0 & $1^{`}(\mathrm{P} 1, \mathrm{M} 1)++1^{`}(\mathrm{P} 2, \mathrm{M} 1)$ & Empty \\
\hline model_1'P4 1 & 1 & 0 & $1 ` \mathrm{P} 1++1{ }^{`} \mathrm{P} 2$ & Empty \\
\hline model_1'P5 1 & 2 & 0 & $1 ` \mathrm{P} 1++1{ }^{`} \mathrm{P} 2$ & Empty \\
\hline model_1'P6 1 & 2 & 0 & $1^{\prime}(\mathrm{P} 3, \mathrm{M} 2)++1^{\prime}(\mathrm{P} 4, \mathrm{M} 2)$ & Empty \\
\hline model_1'P7 1 & 1 & 0 & $1^{\prime}(\mathrm{P} 3, \mathrm{M} 2)++1^{`}(\mathrm{P} 4, \mathrm{M} 2)$ & Empty \\
\hline model_1'P8 1 & 1 & 0 & $1^{`}(\mathrm{P} 3, \mathrm{M} 2)++1^{\prime}(\mathrm{P} 4, \mathrm{M} 2)$ & Empty \\
\hline model_1'P9 1 & 1 & 0 & $1^{`} \mathrm{P} 3++1{ }^{`} \mathrm{P} 4$ & Empty \\
\hline
\end{tabular}




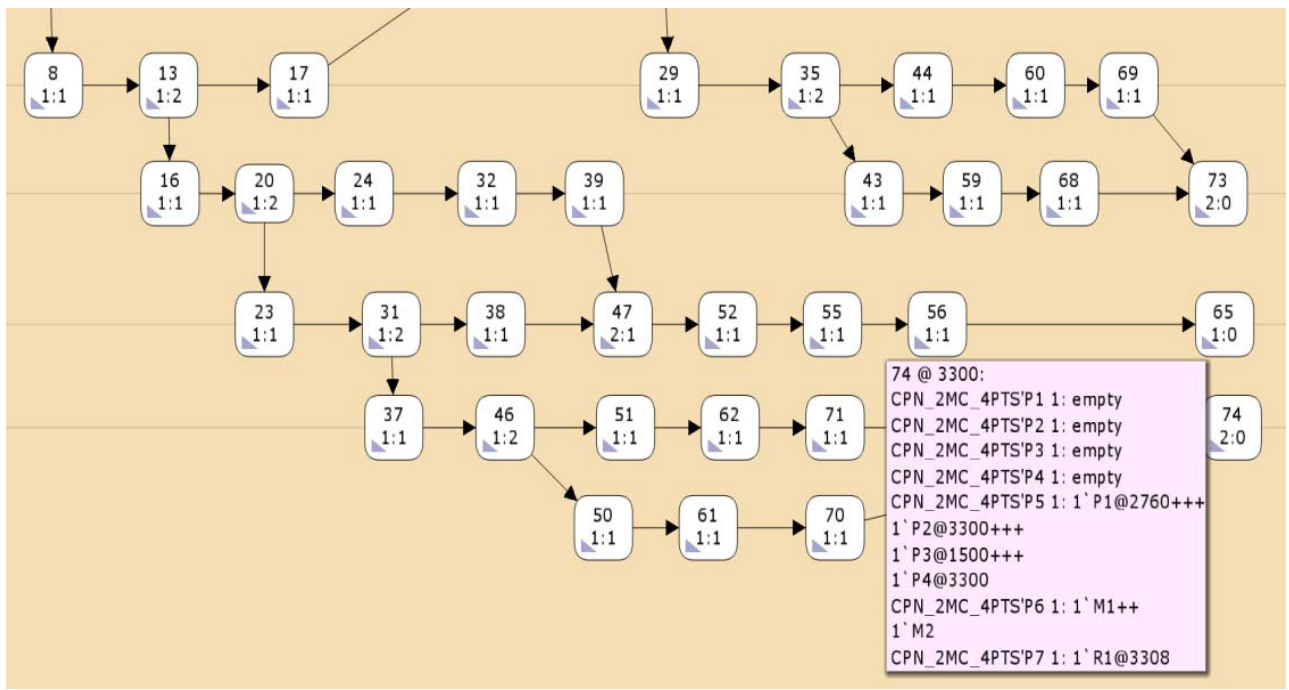

Fig. 8. State space diagram view for compact machine place model.

In Table 8, we present the boundedness properties for the compact machine place and mentioned best possible multi set bounds for the system. Upper bound present the token in each place during the simulation. If we see from the Table 8, CPN_2MC_4PTS'P1 1 its mean place $\mathrm{P} 1$, the token is 4 and the best multi set is $1^{\prime}(\mathrm{P} 1, \mathrm{M} 1)++1{ }^{\prime}(\mathrm{P} 2, \mathrm{M} 1)$ ++1 ' $(\mathrm{P} 3, \mathrm{M} 2)++1^{`}(\mathrm{P} 4, \mathrm{M} 2)$. So, the upper set basically the token in the system.

Table 8. Best Integer Bounds for second Model.

\begin{tabular}{|c|c|c|c|c|}
\hline $\begin{array}{l}\text { Best Integer } \\
\text { Bounds }\end{array}$ & Upper & Lower & $\begin{array}{l}\text { Best Upper Multi-set } \\
\text { Bounds }\end{array}$ & $\begin{array}{l}\text { Best Lower Multi-set } \\
\text { Bounds }\end{array}$ \\
\hline $\begin{array}{l}\text { CPN_2MC_ } \\
\text { 4PTS'P1 } 1\end{array}$ & 4 & 0 & $\begin{array}{c}1^{`}(\mathrm{P} 1, \mathrm{M} 1)++1^{`}(\mathrm{P} 2, \mathrm{M} 1) \\
++1^{`}(\mathrm{P} 3, \mathrm{M} 2)_{++} 1^{`}(\mathrm{P} 4, \mathrm{M} 2)\end{array}$ & Empty \\
\hline $\begin{array}{l}\text { CPN_2MC_ } \\
\text { 4PTS'P2 } 1\end{array}$ & 1 & 0 & $\begin{array}{c}1^{`}(\mathrm{P} 1, \mathrm{M} 1)++1^{`}(\mathrm{P} 2, \mathrm{M} 1) \\
++1^{`}(\mathrm{P} 3, \mathrm{M} 2)++1^{`}(\mathrm{P} 4, \mathrm{M} 2)\end{array}$ & Empty \\
\hline $\begin{array}{l}\text { CPN_2MC_- } \\
\text { 4PTS'P3 } 1\end{array}$ & 2 & 0 & $\begin{array}{c}1^{`}(\mathrm{P} 1, \mathrm{M} 1)++1^{`}(\mathrm{P} 2, \mathrm{M} 1) \\
++1^{`}(\mathrm{P} 3, \mathrm{M} 2)++1^{`}(\mathrm{P} 4, \mathrm{M} 2)\end{array}$ & Empty \\
\hline $\begin{array}{l}\text { CPN_2MC_- } \\
\text { 4PTS'P4 } 1\end{array}$ & 1 & 0 & $1^{\prime} \mathrm{P} 1++1{ }^{\prime} \mathrm{P} 2++1{ }^{\prime} \mathrm{P} 3++1{ }^{\prime} \mathrm{P} 4$ & Empty \\
\hline $\begin{array}{l}\text { CPN_2MC_- } \\
\text { 4PTS'P5 } 1\end{array}$ & 4 & 0 & $1 ` \mathrm{P} 1++1$ 'P2++1 ${ }^{`} \mathrm{P} 3++1{ }^{\prime} \mathrm{P} 4$ & Empty \\
\hline $\begin{array}{l}\text { CPN_2MC_- } \\
\text { 4PTS'P6.1 }\end{array}$ & 2 & 0 & $1 ` \mathrm{M} 1++1{ }^{\prime} \mathrm{M} 2$ & Empty \\
\hline $\begin{array}{l}\text { CPN_2MC_- } \\
\text { 4PTS'P7.1 }\end{array}$ & 1 & 0 & $1 ` \mathrm{R} 1$ & Empty \\
\hline
\end{tabular}




\section{Comparison between the models}

In Table 9, we show the observation from the two different machine place and compact machine place. It's clear that both model results are around similar even the place and transitions are different for both models. So, it's possible to design same model in different way to predict the good results.

Table 9. Comparison between the models.

\begin{tabular}{|c|c|c|}
\hline Parameters & $\begin{array}{c}\text { Two different machine } \\
\text { place }\end{array}$ & Compact machine place \\
\hline No of machine & 2 & 2 \\
\hline No of robot & 1 & 1 \\
\hline No of part processing & 4 & 4 \\
\hline No of place & 13 & 4 \\
\hline No of transition & 8 & 13 \\
\hline No of arcs (in model) & 26 & 78 \\
\hline No of arcs (in state space) & 16 & 74 \\
\hline No of nodes & 17 & 3308 s \\
\hline Total processing time & 1268 s & 16 \\
\hline No of steps to complete & 16 & 6 \\
\hline simulation & 1 & Initial Marking is not a home \\
\hline Dead marking & marking. \\
\hline Home marking & Initial Marking is not a \\
home marking. & No infinite occurrence \\
\hline Fairness Properties & No infinite occurrence & sequences. \\
\hline Dead Transition Instances & None & None \\
\hline Live Transition Instances & None & None \\
\hline
\end{tabular}

\section{Conclusions}

The simulation results from the first system implement with the part processing time with two different positions of machines it shows that 16 steps to take complete the process. The first model we consider only the part processing time. The completion time for the system is $1268 \mathrm{~s}$. For the second model with compact machine place it also took 16 steps to complete the process but the system consider with job arrival time and job processing time. The completion time for the second system is $3308 \mathrm{~s}$. The only difference is the job arrival time for the both models. But the simulation results shows the steps required to complete the simulation is same for both cases. The observation of state space analysis for two different positions of machines shows 17 nodes and 16 arcs and for compact machine place required 74 nodes and 78 arcs to complete the entire process to produce four different parts. Both cases the parts sequence is different. So it is found the system is modeling in different strategic way but the results for required steps are same for both systems. For future works it's possible to construct model using hierarchical timed colored petri net with state space analysis. In manufacturing system the number of processing parts, the number of robots and number of machines increase the quantity of token in the system to make it more complex. 
The paper published has been sponsored under the Erasmus mundus partnership program agreement vide number 2014-0855/001-001 coordinated by and between University of Oradea and City University of London Under Action Plan 2 for the year 2015-18.

\section{References}

1. K. Jensen, LCNS, 483, 75 (1990)

2. K. Jensen, L. M. Kristensen, Coloured Petri nets: modeling and validation of concurrent systems, (Publisher-Springer-Verlag New York Inc. 2009)

3. K. Jensen, L. M. Kristensen, L. Wells, STTT, 9, 42 (2007)

4. K. Jensen, Form. Meth. Syst. Des., 9, 34 (1996)

5. A. V. Ratzer, L. Wells, H. M. Lassen, M. Laursen, J. F. Qvortrup, M. S. Stissing, M. Westergaard, S. Christensen, K. Jensen, Applic. LNCS, 2679, 13 (2003)

6. F. Blaga, I. Stanasel, A. Pop, V. Hule, T. Buidos, Annals of the Oradea University, Fascicle of Management and Technological Engineering, 1, 4 (2014)

7. C. Søren, K. Jensen, T. Mailund, Proc. of 2nd Int. Coll. on Petri Net Technologies for Modelling Communication Based Systems, 12 (2001)

8. C. Li, W. M. Wu, G. Rong, ICNSC, 6 (2014)

9. A. Bevilaqua, E. R. R. Kato, E. C. Pedrino, R. H. Tsunaki, SMC, 6 (2013)

10. M. Aguiar, R. Barreto, R. Caldas, J. Edgar, C. Filho, ICIT, 6 (2008) 